\title{
Stenting of "unprotected" left main coronary artery stenoses: early and late results
}

\author{
C J J Laruelle, G B R Brueren, S M P G Ernst, E T Bal, G E Mast, M-J Suttorp, \\ A Brutel de la Rivière, $\mathrm{T} \mathrm{H}$ W Plokker
}

\begin{abstract}
Objective-To assess short and long term efficacy of coronary stent implantation for unprotected left main coronary artery stenosis.

Design-Retrospective follow up study.

Setting-Tertiary referral centre for interventional cardiology and cardiac surgery.

Patients-Eighteen consecutive patients (12 men; age 70.8 years) between May 1993 and July 1996. Ten patients presented with stable angina and underwent the procedure electively, eight patients presented either with unstable angina or myocardial infarction and underwent the procedure in emergency.

Intervention-Johnson and Johnson Palmaz-Schatz stents were used in 16 patients, and a Microstent and a Gianturco-Roubin in one patient each. An intra-aortic balloon pump was prophylactively used for two patients in the elective group. In the acute group, six required an intra-aortic balloon pump.
\end{abstract}

Main outcome measures-Procedural success rate and major adverse cardiac events.

Results-Successful stent implantation was achieved in all patients. In the elective group, no major adverse cardiac event occurred during the procedure, but one patient had to undergo repeated angioplasty before discharge. All patients of the elective group were discharged alive and there has been one non-cardiac death during a follow up of (mean (SD)) 10 (4) months. In the emergency group, one patient died during the procedure, one patient developed a non $Q$-wave myocardial infarction, one patient underwent emergency coronary bypass surgery, while another patient died suddenly before hospital discharge. Six patients of the emergency group were discharged alive and there has been one non-cardiac death during a follow up of 7 (4) months. Conclusions-Elective stent implantation for unprotected left main coronary artery stenosis is safe and effective in selected stable patients. Urgent stent implantation, however, cannot be considered as a definitive procedure in emergency situation.

(Heart 1998;79:148-152)

Keywords: stent; left main coronary artery disease

In recent years, the indications of percutaneous transluminal coronary angioplasty have been extended to complex and multiple lesions, even in patients with unstable conditions. A so called "unprotected" stenosis of left main coronary artery is still considered to be a contraindication for this procedure. ${ }^{1} \mathrm{Up}$ to now, angioplasty of an unprotected left main coronary supposedly carried a relatively high rate of immediate and long term morbidity and mortality. ${ }^{2}$ There might be a possible role for angioplasty, however, in patients with unprotected left main coronary stenosis with regard to the increase in experience, the progression of technique, and the use of additional devices. ${ }^{3}$ To date, only limited data on angioplasty with stent implantation have been published in the medical literature. ${ }^{45}$ Fajadet et al have shown that for selected patients, stenting of unprotected left main coronary artery stenosis may be an option. ${ }^{5}$ Since the first report of Sigwart et $a l^{6}$ on the placement of stents in the coronary arteries, stenting has been shown to optimise the geometry of the coronary lumen, reducing procedural complications and restenosis. The recent STRESS and Benestent trials demonstrated the effectiveness of the Palmaz-Schatz stent in reducing both the rate of angiographically detected restenosis and the clinical event rate. ${ }^{78}$ Kimura et al demonstrated favourable clinical and angiographic results of stent placement up to three years after the procedure, with low rates of revascularisation of the stented lesions. ${ }^{9}$ Based on these promising findings, unprotected left main coronary artery stenosis could be an attractive lesion for this technique.

We report our immediate and long term follow up results in 18 consecutive patients undergoing stent placement of significant unprotected left main stenosis.

\section{Methods}

PATIENTS (TABLE 1)

Between April 1980 and October 1991-that is, before that availability of stents-we performed percutaneous transluminal coronary angioplasty (PTCA) without stenting for left main coronary artery stenosis in 32 patients. The procedural mortality was $7.7 \%$. Before discharge, $5.6 \%$ of the patients underwent a second PTCA, 2.8\% sustained a $Q$ wave infarction and $2.8 \%$ a non-Q wave infarction. Because of the poor results with conventional balloon angioplasty, all our cases in this study were done with systematic stenting. Retrospectively, we identified all patients who underwent emergency or elective stenting of significant stenosis of unprotected left main coronary artery between 1 March 1993 and 1 July 1996. Information was obtained, by
Accepted for publication 22 September 1997 
Table 1 Baseline variables

\begin{tabular}{|c|c|c|c|c|c|c|c|c|c|c|c|c|c|c|}
\hline Patient & Age & Sex & CCS & Prev $M I$ & $M V D$ & $A d d$ & Morph & $L o c$ & Calc & $\mathrm{Occl}$ & Coll & Dom & $C I C A B G$ & $I A B P$ \\
\hline \multicolumn{15}{|l|}{ Elective } \\
\hline 1 & 57 & $\mathrm{~F}$ & III & - & LAD & LAD & Conc & $\mathrm{O}$ & - & - & - & $\mathrm{R}$ & - & - \\
\hline 2 & 68 & $M$ & III & - & LAD & LAD & Conc & $\mathrm{O}$ & - & - & - & $\mathrm{R}$ & - & - \\
\hline 3 & 69 & M & III & - & - & - & Conc & M & - & - & - & $\mathrm{R}$ & + & - \\
\hline 4 & 58 & $M$ & III & - & RCA & - & Exc & $M$ & + & - & - & $\mathrm{R}$ & - & + \\
\hline 5 & 86 & $\mathrm{~F}$ & IV & - & $\begin{array}{l}\text { RCA } \\
\text { LAD } \\
\text { MO }\end{array}$ & - & Conc & $\mathrm{O}$ & + & - & + & $\mathrm{R}$ & + & - \\
\hline 6 & 75 & $\mathrm{~F}$ & III & - & $\mathrm{RCX}$ & - & Conc & M & + & - & - & $\mathrm{L}$ & + & - \\
\hline 7 & 57 & M & III & - & PLCX & - & Exc & M & - & - & - & $\mathrm{L}$ & - & - \\
\hline 8 & 67 & M & III & - & - & - & Exc & $\mathrm{O}$ & - & - & - & $\mathrm{L}$ & - & - \\
\hline 9 & 79 & $\mathrm{~F}$ & IV & Ant & - & - & Exc & $\mathrm{O}$ & + & - & - & $\mathrm{R}$ & - & + \\
\hline 10 & 39 & $\mathrm{M}$ & III & - & - & - & Conc & M & - & - & - & $\mathrm{R}$ & - & - \\
\hline \multicolumn{15}{|c|}{ Emergency } \\
\hline 1 & 55 & M & III & - & $\begin{array}{l}\text { RCA } \\
\mathrm{MO}\end{array}$ & $\begin{array}{l}\text { RCA } \\
\text { MO }\end{array}$ & Exc & M & - & - & - & $\mathrm{R}$ & - & + \\
\hline 2 & 79 & M & IV & - & - & - & occl & $M$ & - & + & - & $\mathrm{R}$ & - & + \\
\hline 3 & 73 & $\mathrm{~F}$ & II & - & LAD & LAD & Conc & $\mathrm{O}$ & - & - & - & $\mathrm{R}$ & - & + \\
\hline 4 & 79 & M & IV & - & - & - & occl & M & + & + & + & $\mathrm{R}$ & - & - \\
\hline 5 & 74 & M & IV & - & RCA & - & Exc & $\mathrm{O}$ & + & - & - & $\mathrm{L}$ & - & + \\
\hline 6 & 81 & M & III & - & - & - & Exc & $\mathrm{O}$ & - & - & - & $\mathrm{R}$ & + & - \\
\hline 7 & 88 & M & IV & - & $\begin{array}{l}\text { RCA } \\
\text { RCX }\end{array}$ & $\begin{array}{l}\text { RCA } \\
\text { RCX }\end{array}$ & Exc & M & - & - & - & $\mathrm{R}$ & - & + \\
\hline 8 & 91 & $\mathrm{~F}$ & IV & - & RCA & RCA & Exc & $M$ & + & - & + & $\mathrm{R}$ & + & + \\
\hline
\end{tabular}

CCS, angina class; Prev MI, previous myocardial infarction; MVD, multiple vessel disease; Add, additional angioplasty during the same procedure; Morph, morphology; Loc, localisation; Calc, calcification; Occl, occlusion; Coll, collateral; Dom, dominance; CI CABG, contraindication for coronary artery bypass surgery; IABP, intra-aortic balloon pump; Ant, anterior; LAD, left anterior descending; RCA, right coronary artery; LCX, left circumflex; Conc, concentric; Exc, excentric; O, ostial; $\mathrm{M}$, mid; R, right; L, left.

reviewing hospital charts, cineangiographic films, and reports of the angioplasty database of a total of 5200 angioplasty procedures performed within that period of time. During the study period, 285 patients underwent elective or urgent bypass surgery for left main coronary artery stenosis at our institution. Follow up information was obtained through return visits, correspondence, and telephone interviews.

Stenting of unprotected left main coronary stenosis was performed in 18 patients. There were 12 men and six women. The mean age was 70.8 years (range 38-91). All patients had angina class CCS III or IV, except one with class II. One patient had suffered from a previous myocardial infarction, in an area supplied via the left main coronary artery. Seven patients had a unique lesion of the left main coronary artery, 11 had concomitant multiple vessel disease. Five patients were considered to have contraindication for surgical revascularisation such as disseminated carcinoma, extreme age, and Jehovah witness. Eight patients underwent emergency angioplasty because of acute myocardial infarction (four patients) or unstable angina associated in three of them with cardiogenic shock. Table 1 summarises baseline characteristics of the population and morphology of the stenosis. Two emergency patients had a total occlusion of the left main coronary artery. In two patients, the left ventricular function was unknown, because of the emergency situation. Two patients had an impaired left ventricular function, all other patients had a normal left ventricular function. No patient had undergone previous angioplasty.

\section{TECHNICAL APPROACH}

All procedures were performed using the standard percutaneous transfemoral approach, using an over the wire dilatation system, with
0.014 inch intracoronary guidewires. Balloon catheters capable of maintaining high balloon pressure were preferred. Johnson and Johnson Palmaz-Schatz stents ( $9 \mathrm{~mm}$ in length) were used for 16 patients, one patient received a MICRO stent, another a Gianturco Roubin stent. One patient was first treated, in the same setting, with a Rotablator because of an excentric, calcified ostial stenosis. In six patients of the emergency group and in two patients from the elective group, an intra-aortic balloon pump was placed before the procedure. During the procedure, the patients received $10000 \mathrm{U}$ heparin intravenously. After the procedure, the patients were maintained on heparin by constant infusion with subsequent adjustment. A continuous drip with low molecular weight dextran was also given. During and after the dilatation, glyceryl trinitrate was given intravenously during four hours. After the angioplasty, all patients received oral anticoagulants, aspirin, and a calcium entry blocker.

Follow up angiography was performed only in case of signs of ischaemia.

\section{DATA ANALYSIS}

Left main coronary artery stenosis was defined as a more than $70 \%$ stenosis assessed visually by coronary angiography. The angioplasty procedure was considered as successful when a reduction of at least $20 \%$ in luminal diameter narrowing and a residual stenosis of less than $20 \%$ was obtained without major complications (death, acute myocardial infarction, coronary artery bypass surgery, repeat angioplasty). Restenosis was defined as a minimal diameter stenosis of more than $50 \%$ at the time of angiographic follow up. Baseline global left ventricular function was assessed qualitatively by contrast ventriculography and categorised as normal or impaired using the CASS classification. 
Table 2 Results

\begin{tabular}{lll}
\hline & Elective patients & Emergency patients \\
\hline $\begin{array}{l}\text { Procedural data } \\
\text { Procedural success }\end{array}$ & $100 \%$ & $100 \%$ \\
Additional PTCA & $\mathrm{n}=2$ & $\mathrm{n}=4$ \\
Complications & 0 & $\begin{array}{l}1 \text { death, } 1 \text { urgent CABG, } 1 \text { non-Q } \\
\text { wave } \mathrm{MI}\end{array}$ \\
In-hospital events & 1 repeat PTCA & $\begin{array}{l}1 \text { sudden death } \\
6.5(4.4)\end{array}$ \\
Mean (SD) follow up (months) & $10(4.3)$ & $\begin{array}{l}1 \text { non-related death, } 1 \text { patient } \\
\text { Events }\end{array}$ \\
& 1 non-related death & \\
\end{tabular}

\section{Results (table 2)}

PROCEDURAL AND INTRA-HOSPITAL RESULTS

Elective subgroup

Of the 10 consecutive elective procedures, successful left main coronary artery stenting was achieved in all patients (100\%). Figures 1 and 2 show an example of stent implantation. An intra-aortic balloon was used prophylactically for two patients. In one case, Rotablator atherectomy was used because of dense calcifications. Additional stenoses in the left anterior descending coronary artery were successfully dilated in two patients. There were no procedural complications. During the stay in hospital, one patient who suffered from a non- $Q$ wave lateral myocardial infarction after the procedure underwent successful PTCA of a proximal left circumflex stenosis caused by partial protrusion of the stent into the bifurcation; death, coronary artery bypass surgery, repeat angioplasty of the main coronary artery were not seen during the hospital phase.

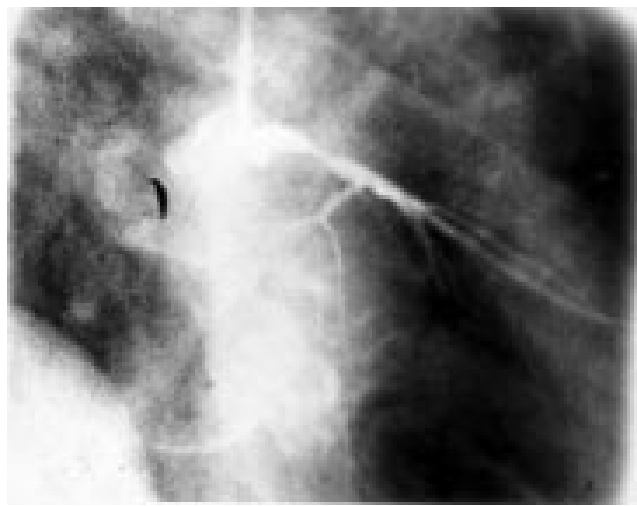

Figure 1 Left main coronary artery stenosis in right oblique view.

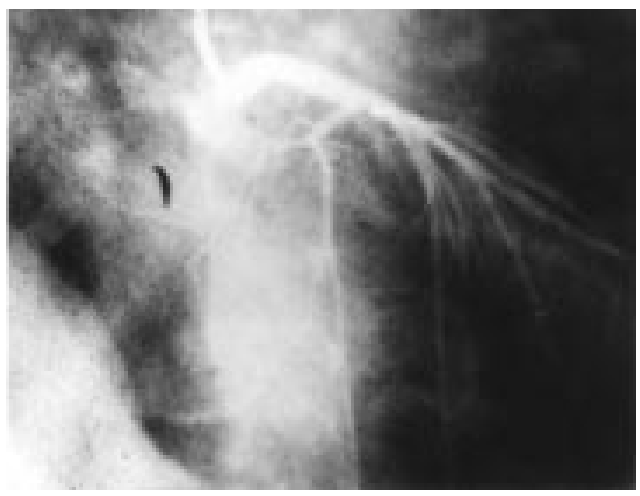

Figure 2 Left main coronary artery after stent implantation in right oblique view.
Emergency subgroup

Three patients were in cardiogenic shock, four had unstable angina, and six required an intraaortic balloon pump (75\%). Successful stenting was accomplished in all patients. During the procedure, additional stenoses were successfully dilated in four patients, two in the right coronary artery and left circumflex, one in the left anterior descending coronary artery, one in the right coronary artery. One patient, temporarily stabilised by successful stenting of severe left main artery stenosis, and angioplasty of the equally severe stenosis right coronary artery and ramus circumflexus was transferred for successful emergency surgical revascularisation, because of persistent shock. Another died immediately after the procedure, because of persisting cardiogenic shock, and one patient developed a non-Q wave myocardial infarction. One patient died suddenly during hospital stay. The four patients with acute myocardial infarction (two anterior and two non-Q wave myocardial infarction) have a particularly poor outcome, two died, one underwent emergency coronary artery bypass surgery, and the fourth one is alive and free of symptoms.

\section{Procedural factors}

In 12 of 18 patients, more than one balloon was needed. The mean maximum inflated balloon size was $4.3 \mathrm{~mm}$ (range 3.5-5.5), using a balloon capable of maintaining high pressure rate. The mean maximal inflation pressure was at least 16 atmospheres. In all patients, there was an improved antegrade flow through the LM and the left coronary system, and no technical complication was noted.

LATE RESULTS

Late follow up data were available in all patients. The mean (SD) duration of follow up was 10 (4.3) months in the elective group and 6.5 (4.4) months in the acute group. Table 2 lists the follow up data. At the time of follow up, no patient had suffered from a non-fatal acute myocardial infarction, no repeat angioplasty and no acute or elective surgical revascularisation was required. Two deaths were noted during the follow up period, one in each group, none was of cardiac origin; these two patients developed major stroke. One patient in the emergency group developed functional angina class II within the first six months. This patient had undergone additional angioplasty on the left anterior descending coronary artery during the initial procedure. Control angiography was performed nine months after the procedure and showed restenosis in the left anterior descending coronary artery; in the left main coronary artery, no restenosis was seen. The 12 living patients were free of symptoms at follow up.

\section{Discussion}

Stenosis of the left main coronary artery is the most lethal manifestation of coronary atherosclerosis, occurring in $5 \%$ of patients with stable angina and in $7 \%$ of patients with recent myocardial infarction. Previous studies have shown a three year death rate up to $50 \%$ for 
medically treated patients with angiographically demonstrated left main coronary artery disease. ${ }^{10}$ Coronary artery bypass surgery has been shown to significantly improve survival, but it is among the highest risk group for coronary artery bypass surgery. Results of the CASS study show an overall operative mortality of $3.5 \%$, which tends to be higher when the stenosis is more severe and when a larger myocardial territory is in jeopardy. ${ }^{11}{ }^{12}$ The results of surgical angioplasty of the left main coronary artery are comparable to those achieved by conventional grafting. ${ }^{13}$

The left main coronary artery is certainly an inviting target for coronary angioplasty, because of its proximal position and large dimensions. Early experiences, however, have shown high procedural and short-term death rates for balloon angioplasty procedures. ${ }^{12}$ O'Keefe et al reported a procedural mortality in unprotected left main coronary artery of $9.1 \%$ and a three year survival of only $30 \% .^{2}$ The introduction of stents has modified interventional cardiology with regard to both short-term success rates and long term outcomes. Thus stenting of unprotected left main coronary artery stenosis seems to be an attractive therapeutic tool for this group of patients, because the stent gives protection against local complications such as recoil and dissection, and helps to prevent restenosis.

Our results support stenting of unprotected left main coronary artery stenosis, as a revascularisation option in elective conditions. From our results and the experience of others, ${ }^{514}$ it can be concluded that this approach can be considered as feasible, safe, and effective in the elective group. The primary success rate in our patients was comparable with the overall success rate of angioplasty in major coronary arteries. One non- $Q$ wave acute myocardial infarction was noted, this patient underwent repeat angioplasty of the proximal left circumflex, because the stent protruded in the bifurcation resulting in a partial obstruction of the left circumflex. During follow up, no major cardiac events occurred. One patient died because of major central nervous ischaemic episodes.

In the emergency group however, a high rate of major events during the hospital stay was noted. Two patients died, one developed a non-Q wave myocardial infarction, and one underwent urgent surgical revascularisation with good results also at follow up. During follow up, no major cardiac event was seen. One patient died because of an unrelated cause, one developed angina pectoris (CCS class II), three remained free of symptoms.

Technically, with experienced operators, unprotected left main coronary artery stenting is an easy procedure. Most of our patients underwent elective stenting without support of an intra-aortic balloon pump and without double wire technique. In the elective group, there were two patients in whom the intra-aortic balloon pump was electively used. Both were cases in whom a long procedural time was anticipated, namely in the patient in whom rotablator was used and in a second patient who had additional significant lesion of the right coronary artery.

In most circumstances, we orient the guidewire in the left descending artery. High pressure rates used in our laboratory to obtain maximal stent expansion in such large coronary arteries, and the use of a short stent without protrusion in the bifurcation of the left main coronary artery have certainly contributed to our favourable results. Using a single, short (one minute), high pressure inflation for stent delivery, no patient suffered from cardiovascular collapse. Also the lesion morphology is important in the selection of the patients. We have selected ostial or mid-left main coronary artery lesions carefully excluding bifurcation lesions, and diffuse disease. The size of circumflexes was not an anatomic exclusion criteria.

The prognostic differences between the two groups (elective and urgent) can probably be explained by different reasons. Firstly, there are considerable differences in the population's characteristics. The mean age is higher in the acute group (65.5 versus 77.5 years), and the proportions of multiple vessels disease and multiple angioplasty during the same initial procedure are also higher. The prognosis of revascularisation procedure is also worse in acute conditions and certainly when a larger myocardial territory is in jeopardy. Both conditions were present in all eight patients who were in cardiogenic shock or in severe unstable angina.

These data should be interpreted cautiously, however, because selection bias and the comparatively small number of patients may have contributed to these favourable results. Furthermore, this is a retrospective study, without simultaneously randomised control group.

This study shows that elective stenting of unprotected left main coronary artery stenosis can be performed with a high success rate, low complication rate, and suggests that it is a viable revascularisation option in elective cases. Larger series should clarify whether unprotected left main coronary artery stenting has the same favourable results as coronary artery bypass surgery. Emergency stenting of such lesions may be an important alternative approach for patients with acute unstable conditions or cardiogenic shock, and may be life saving, although subsequently elective bypass surgery may still be needed. Given our results, it should not be considered as a definitive procedure in emergency situations.

1 A Report from the ACC/AHA Task Force. Guidelines for percutaneous transluminal angioplasty. Circulation percutaneous tran

2 O'Keefe JH, Hartzler GO, Rutherford BD, et al. Left main coronary angioplasty: early and late results of 127 acute and elective procedures. Am $\mathcal{F}$ Cardiol 1989;64:144-7.

3 Eldar M, Schulhoff N, Herz I, et al. Results of percutaneous transluminal angioplasty of the left main coronary artery. Am f Cardiol 1991;68:255-6.

4 Macaya C, Fernando A, Iniques A, et al. Stenting for elastic recoil during coronary angioplasty of the left main coronary artery. Am f Cardiol 1992;70:105-7.

5 Fajadet J, Brunel P, Jourdan C, et al. Stenting of unprotected left main coronary artery stenosis without coumadin. $\mathcal{F} \mathrm{Am}$ Coll Cardiol 1996;277A:772.

6 Sigwart U, Puel J, Mirkovitch V, Joffre F, et al. Intravascular stents to prevent occlusion and restenosis after transluminal angioplasty. $N$ Engl F Med 1987;316:701-6. 
7 Serruys PW, de Jagere P, Kiemeneij F, et al for the Benestent Study Group. A comparison of balloon expandable stent implantation with balloon angioplasty in patients with coronary artery disease. N Engl f Med 1994;331:489-95.

8 Fischman DL, Leon BM, Baim SD, et al for the Stent Restenosis Study Investigators. A randomized comparison of coronary stent placement and balloon angioplasty in the treatment of coronary artery disease. $N$ Engl $f \mathrm{Med}$ 1994;331:496-501.

9 Kimura R, Tokeshi K, Hirogoshi Y, et al. Three years follow-up after implantation of metallic coronary artery stents. N Engl F Med 1996;334:561-6.

10 Conley MJ, Ely RL, Kisslo J, et al. The prognostic spectrum of left main stenosis. Circulation 1978;57:947-52.

11 Chairman BR, Fisher LD, Bourassa MG, et al. Effect of coronary bypass surgery on survival patterns in patients with left main coronary artery disease. Report of the Collaborative Study in Coronary Artery Surgery (CASS). Am f Cardiol 1981;48:765-77.

12 Takaro T, Peduzzi P, Detre KM, et al. Survival in subgroups with left main coronary disease: VA Cooperative Study of Surgery for Coronary Artery Disease. Circulation 1982;66: 14-22.

13 Dion R, Verhelst R, Matta A, et al. Surgical angioplasty of the left main coronary artery. $\mathcal{F}$ Thorac Cardiovasc Surg 1990;99:241-50.

14 Stertzer SH, Migler PK, Insel H, et al. Percutaneous transluminal coronary angioplasty in left coronary stenosis: a five-year appraisal. Int f Cardiol 1985;9:149-59. 